\title{
Rancang Bangun Jangkar Motor DC
}

\author{
(The Rotor of DC Motor Design)
}

\author{
Moh. Nur Yuski, Widyono Hadi, Azmi Saleh \\ Jurusan Teknik Elektro, Fakultas Teknik, Universitas Jember (UNEJ) \\ Jln. Kalimantan 37, Jember 68121 \\ E-mail:nur.yuski@gmail.com
}

\begin{abstract}
Abstrak
Motor Dc adalah salah satu motor listrik yang saat ini sering digunakan. Dengan kemajuan teknologi saat ini motor DC dituntut untuk memiliki karakteristik yang handal dan efesien. Untuk memperoleh karateristik yang handal dan efisien telah banyak dilakukan pengaturan dan modifikasi terhadap motor DC, baik pada Stator maupun padaRotor (jangkar). Pada penelitian ini dilakukan rancang bangung jangkar motor DC agar memperoleh karakteristik motor yang handal dan efisien. Metode yang digunakan adalah dengan merubah sudut dan arah alur jangkar Motor Dc. Motor de normal yang awalanya memiliki alur lurus dirubah arahnya ke kanan dan ke kiri sebesar $30^{\circ}$. Hasil yang diperoleh dari hasil pengujian motor dc tanpa menggunakan beban dengan motor dc bekerja saat tegangan nominal $24 \mathrm{~V}$, diperoeleh karateristik arus dan daya pada motor DC Normal, miring Ke kanan dan miring ke kiri sama yaitu sebesar 0,17 A dan 4,08 watt. Sedangkan untuk karakteristik nilai RPM dan Torsi saat motor DC bekerja pada tegangan nominal $24 \mathrm{v}$, diperoleh nilai yang berbeda untuk motor de normal 3569 RPM dan 0,01092 Nm, untuk motor DC miring kanan 3823 RPM dan 0,0102 Nm, serta untuk motor dc miring kiri 3849 RPM dan 0,0102 Nm. Dengan memiringkan alur jangkar sebesar 30 derajat akan memperoleh nilai RPM yang lebih besar dibanding dengan alur lurus baik ke dimiringkan ke kanan maupun ke kiri. Sedangkan untuk nilai torsi alur lurus memiliki nilai torsi yang lebih besar dibanding dengan alur jangkar yang telah dimiringkan 30 derajat baik ke kanan maupun ke kiri. Dengan besar sudut alur jangkar dan arah sudut berbeda memiliki nilai RPM dan Torsi yang sama.
\end{abstract}

Kata Kunci: Motor DC, Jangkar, Alur, Sudut, RPM, Torsi.

\section{Abstract}

Dc motors are one of the electric motors are now often used. With the advancement of technology today DC motors are required to have characteristics that are reliable and efficient. To obtain a reliable and efficient characteristics have been carried settings and modifications to the DC motor, both the stator and the rotor. In this research rotor of DC motor design in order to obtain motor characteristics that are reliable and efficient. The method used is to change the angle and direction of plot of the rotor of Motor Dc. Normal dc motor that originally had a straight plot changed its direction to the right and to the left of $30^{\circ}$. The results obtained from the test results without using a dc motor with a motor load dc current work $24 \mathrm{~V}$ nominal voltage, current and power characteristics diperoeleh on Normal DC motors, sloping Go right and tilted to the left the same, namely $0.17 \mathrm{~A}$ and 4.08 watts, As for the value of RPM and torque characteristics of a DC motor when working at a nominal voltage of $24 \mathrm{~V}$, the different values obtained for normal dc motor $3569 \mathrm{RPM}$ and $0.01092 \mathrm{Nm}$, for DC motor $3823 \mathrm{RPM}$ right slant and $0.0102 \mathrm{Nm}$, as well as to the dc motor left oblique $3849 \mathrm{RPM}$ and $0.0102 \mathrm{Nm}$. By tilting the rotor plot of 30 degrees will be granted RPM greater than with straight plot either to be tilted to the right or to the left. As for the value of torque straight plot has a torque value greater than the plot of rotor that has been tilted 30 degrees either to the right or to the left. With a large angle and direction of the rotor plot have different angles RPM and torque values are the same.

Keywords: DC motor, rotor, plot, angle, RPM, Torque.

\section{PENDAHULUAN}

Pada zaman modern ini manusia banyak bergantung pada motor listrik. Penggunaan motor listrik telah meliputi berbagai bidang mulai dari peralatan rumah tangga, peralatan industri, robot, pesawat, komputer dan alatelektronik lainnya membutuhkan motor listrik sebagai penggerak. Dengan perkembangan kemajuan teknologi motor saat ini diharapkan motor dapat memiliki karakteristik yang handal dan efisien yang maksimal. Untuk mencapai hal ini dapat dilakukan dengan modifikasi pada beberapa bagian motor sehingga mampu bekerja dengan baik dan efisien maksimal.

Motor dc adalah salah satu jenis motor listrik yang saat ini sering digunakan. Motor DC memerlukan suplai tegangan yang searah pada kumparan medan untuk diubah menjadi energi mekanik. Konstruksi motor DC terdiri dari dua bagian yaitu stator dan rotor. Kumparan medan pada motor dc disebut stator (bagian yang tidak berputar) dan kumparan jangkar disebut rotor (bagian yang berputar). Jika terjadi putaran pada kumparan jangkar dalam pada medan magnet, maka akan timbul tegangan (Gaya gerak listrik) yang berubah-ubah arah pada setiap setengah putaran, sehingga merupakan tegangan bolak-balik. Prinsip kerja dari arus searah adalah membalik phasa tegangan dari gelombang yang mempunyai nilai positif dengan menggunakan komutator, dengan demikian arus yang 
berbalik arah dengan kumparan jangkar yang berputar dalam medan magnet. HF. Emil Lenz pada tahun 1834 menuliskan bahwa "arus induksi selalu berlawanan arah dengan gerakan atau perubahan yang menyebabkannya". Timbulnya gaya gerak listrik tergantung pada kekuatan garis fluks magnet, jumlah lilitan konduktor, sudut perpotongan fluks magnet dengan konduktor dan kecepatan konduktor memotong garis fluks magnet.

Saat ini, banyak dilakukan pengaturan dan modifikasi terhadap konstruksi mortor dc baik bagian rotor maupun stator. Pada penelitian sebelumnya "Kajian pengaruh modifikasi jumlah kutub terhadap perubahan daya dan torsi motor induksi satu fasa"[1]. Pada penelitian tersebut dilakukan modifikasi pada bagian stator dan menggunakan motor induksi sebagai objek penelitian. Hal ini dilakukan agar memperoleh kecepatan, torsi dan daya pada motor yang sesuai dengan kebutuhan. Penelitian sebelumnya juga ada yang menggunakan motor DC “analisis motor dc seri akibat dari pergesran sikat"[2]. Kinerja suatu motor di katakan baik jika memiliki karakteristik dan efisiensi yang tinggi. Karakteristikdan efisiensi yang tinggi dapat dicapai dengan mengatur bagian-bagian tertentu dari motor. Pengaturan pergeseran letak sikat dalam mengantisipasi reaksi jangkar ternyata berpengaruh pada kinerja motor serta efisiensi dari motot tersebut [2].

Namun, untuk penelitian kali ini penulis akan melakukan penelitian pada bagian rotor dan menggunakan motor DC sebagai objek penelitian. Pada jangkar rotor motor terdapat konduktor yang diletakkan di alur-alur rotor. Oleh karena itu akan dilakukan analisis pengaruh perubahan sudut kemiringan alur pada motor DC jenis rotor sangkar terhadap besar nilai kecepatan dan torsi. Sehingga diperlukan perancangan rotor motor dc dengan sudut kemeringan baru untuk memperoleh karakteristik kecepatan dan torsi yang sesuai.

\section{TINJAUAN PUSTAKA}

\section{A. Motor DC magnet permanen}

Motor DC magnet permanen adalah motor arus searah dengan stator yang menggunakan magnet permanen. Medan magnet didefenisikan sebagai daerah atau wilayah yang jika sebuah benda bermuatan listrik berada pada atau bergerak didaerah itu maka benda tersebut akan mendapatkan gaya magnetic. Adanya medan magnetic disekitar arus listrik dibuktikan oleh Hans Christian Oersted melalui percobaan. Gaya yang diberikan satu magnet terhadap yang lainnya dapat dideskripsikan sebagai interaksi antara suatu magnet dan medan magnet dari yang lain.[3]

$$
T=F \quad r \sin \theta
$$

Ket :

$$
\begin{aligned}
& \mathrm{T}=\text { Torsi } \\
& \mathrm{F}=\text { Gaya }=\text { B.I.L } \\
& \mathrm{r}=\text { Jari-jari } \\
& \theta=\text { sudut } \\
& \quad n=\frac{P \quad \times 60}{T \times 2 \pi}
\end{aligned}
$$

Ket : $\quad \mathrm{n}=$ Kecepatan Putar $(\mathrm{Rpm})$ $P=$ Daya (watt)

$$
\text { Ket : } \quad \begin{aligned}
& E_{a}=\text { Tegangan Jangkar } \\
& I_{a}=\text { Arus Jangkar } \\
& \omega_{m}=\frac{2 \pi n}{60}, \text { Kecepatan sudut [4] }
\end{aligned}
$$

\section{B. Konstruksi Motor DC}

\section{Stator Motor DC}

Stator adalah bagian yang berfungsi sebagai rangkaian magnetik yang mempunyai sepasang kutub medan yang terpasang pada bagian dalam stator. Digambarkan pada gambar 1(a).

2. Jangkar atau rotor motor DC

Jangkar atau Jangkar berfungsi untuk merubah energi listrik menjadi energi gerak dalam bentuk gerak putar. Jangkar terdiri dari poros baja dimana tumpukan kepingkeping inti yang berbentuk silinder dijepit. Pada inti jangkar terdapat aur-alur dimana lilitan jangkar diletakkan. Digambarkan pada gambar 1(b).

\section{Komutator}

Konstruksi dari komutator terdiri dari batangan tembaga yang dikeraskan (drop forged) yang diisolasi dengan sejenis mika. Fungsi komutator ini adalah mengumpulkan arus induksi dari konduktor jangkar dan mengkonversikan menjadi arus searah melalui sikat. Secara mekanik motor DC merupakan alat yang komplek dan cenderung banyak persoalan. Sebagai contoh, kotoran pada komutator, dapat menghambat suplai listrik menuju jangkar. Beberapa jenis perawatan dibutuhkan pada saat menggunakan motor DC, pada beberapa pemakaian dengan lingkungan tertentu. Misalnya pada lingkungan asam, akan memunculkan karat yang dapat merusak komutator. Akibatnya, gesekan antara karbon dan komutator dapat menyebabkan arus jangkar yang dapat membahayakan. Digambarkan pada gambar 1(c). [3]

\section{Sikat (Brush)}

Sikat digambarkan pada gambar 1(d) terbuat dari karbon, graphite, logam graphite atau campuran karbon dan grafit yang dilengkapi dengan pegas penekanan dan kontak sikatnya. Sikat biasanya dipasang dengan menumpangkannya pada sisi komutator untuk menyuplai listrik ke motor.[5]

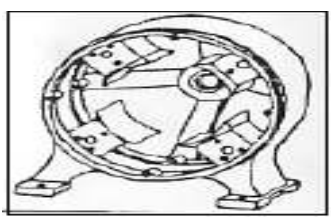

(a)

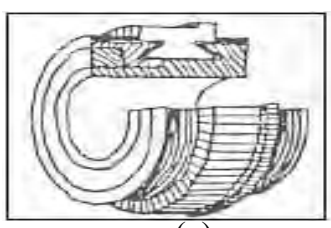

(c)

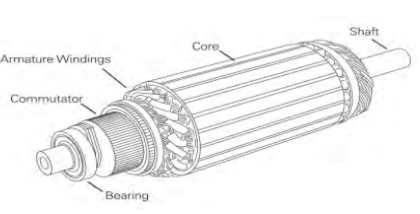

(b)

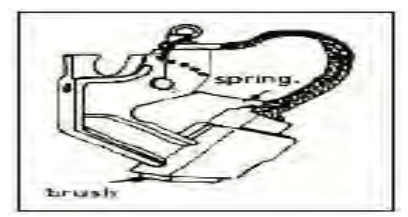

(d)
Gambar 1. Stator (a), Rotor (b), Komutator (c) Sikat (d) Pada Motor DC 


\section{METODE PENELITIAN}

\section{A. Diagram Blok Sistem}

Pada penelitian ini, menggunakan diagram blok sistem pada Gambar 3 yang merupakan alur perancangan modifikasi rancang bangun jangkar motor DC. Identifikasi dilakukan pada konstruksi stator maupun rotor untuk mengetahui jumlah kutub, jumlah lilitan, jenis lilitan, jumlah alur, diameter jankar, kondisi komutator, kondisi poros jangkar, kondisi sikat arang, dan fluks medan magnet permanen. Setelah dilakukan identifikasi terhadap konstruksi motor DC dan memisahkan stator dengan rotor, kemudian melepaskan lilitan dari jangkarnya. Stator yang sudah terpisah dari lilitannya akan dilakukan modifikasi untuk memiringkan alur pada jangkar. Sebelum memiringkan alur, jangkar harus dipisah menjadi kepingan-kepingan agar meudahkan untuk memiringkan alur $30^{\circ}$. Barulah stator dan rotor bisa digabungkan setelah dilakukan penglilitan ulang. motor DC yang telah dimodifikasi dapat dilakukan pengujian.

\section{B. Flow Chart}

Pada penelitian ini, menggunakan Flow chart sistem pada Gambar 4 yang merupakan alur perancangan modifikasi rancang bangun jangkar motor DC.

\section{Gambar Rancanagan Motor DC Modifikasi}

Pada penelitian ini menggunakan gambaran rancangan rotor motor DC. Pada gambar 5 menunjukan jangkar dengan alur luru (a), alur miring kanan 30 derajat (b) dan alur miring kiri 30 derajat ke kiri (c).

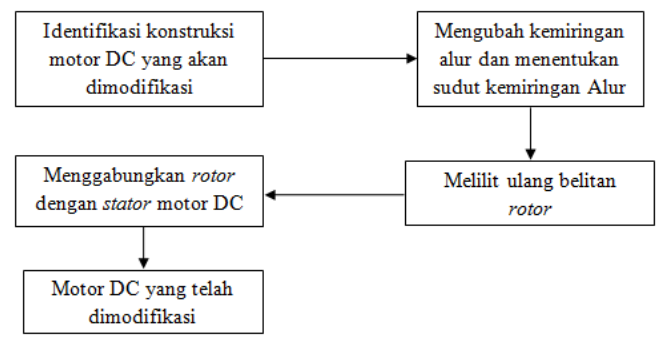

Gambar 3. Blok diagrm penelitian

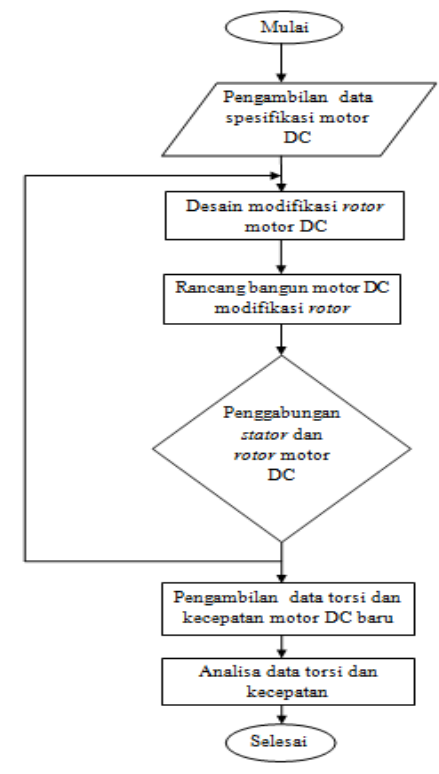

Gambar 4. Flow chart

\section{Konstruksi Penelitian}

Pada penelitian ini Untuk stator motor dc konstruksi terdiri dari 2 kutub magnet permanent. Magnet tersebut memilki nilai fluks 0,00345 fluks dan luas penampang 0,000539 meter kubik. Untuk konstruksi jangkar motor DC magnet permnen terdiri dari inti jangkar, alur jangkar, kumparan jangkar, sikat arang dan komutator. Inti jangkar pada motor DC ini terbuat baja silikon. Alur jangkar pada motor DC ini terdiri dari 7 alur, yang masing-masing alur ditempati kumparan jangkar sebanyak 54 lilitan. Untuk total seluruh kumparan jangkar ialah 378 lilitan. Untuk kawat tembaga yang digunakan yaitu jenis supreme, diameter tembaga yang digunakan $0,35 \mathrm{~mm}$. Konstruksi motor dc nisca NC5475C dapat dilihat pada gambar 6.

Penelitian ini akan memiringkan alur jangkar pada motor DC. Untuk motor pertama akan dimiringkan ke kanan sebesar 30 derajat dan yang kedua dimiringkan ke kiri sebesar 30 derajat. Dengan motor DC alur jangkar lurus sebagai acuan penelitian. Setelah kumparan jangkar selesai digulung, maka dilakukan penggabungan stator dengan jangkar motor DC dan dilakukan pengujian motor DC

\section{E. Spesifikasi Motor DC}

Pada penelitian ini motor DC yang digunakan memiliki spesifikasi motor yang ditunjukan pada tabel 1 .

Tabel 1. Spesifikasi motor DC nisca model NC5475
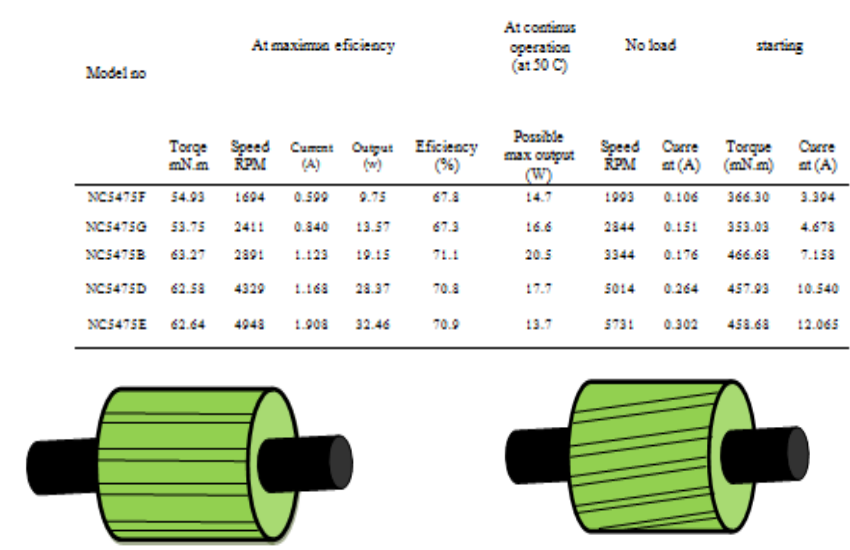

(a)

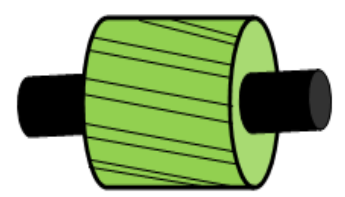

(b)

Gambar 5. Rancangan rotor motor DC

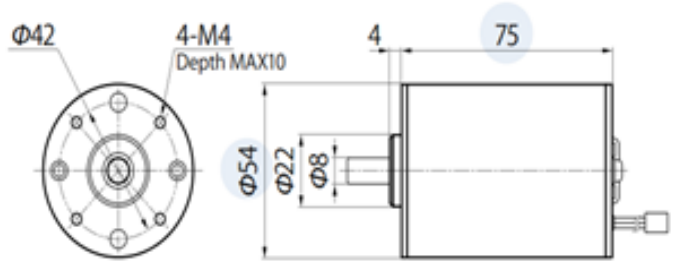

Gambar 6. Konstruksi Motor DC nisca model NC5475 


\section{HASIL PENELITIAN}

\section{A. Perancangan Alur Miring Jangkar Motor DC}

Pada gambar 7. Merupakan hasil modifikasi rancang bangun jangkar motor DC. Proses awal pada rancang bangun rotor motor DC ini ialah memiringkan alur rotor. Untuk memiringkan alur pada rotor pertama harus melepaskan jangkar dari porosnya. Pertama memisahkan rotor dengn stator mtor terlebih dahulu. Sebelum melakukan perlakuan apapun terhadap rotor yang akan dilakukan perubahan maka diambil karakteristik konstruksi pada rotor tersebut. Pada penelitian ini digunakan motor DC $24 \mathrm{~V}$ dengan karaketrisrik konstruksi pada rotor yaitu jumlah alur 7, lilitan 54, diameter tembaga $0,35 \mathrm{~mm}$, panjang jangkar $\mathrm{cm}$ dan konstruksi kumpuran yang digunakan kumparan jerat. Sedangkan stator menggunakan magnet permanet 2 kutub. Untuk penelitian ini yang berubah hanya posisi alur pada rotor yang awalnya lurus akan dimiringkan, jadi untuk karakteristik konstruksi pada motor ini tetap.

Dalam membuka jangkar menggunakan alat pembuka puller ( traker ) yaitu alat pembuka bering. Agar memudahkan dalam memiringkan alur yang lurus maka keren (lempengan-lempengan jangkar) dilepas satu persatu untuk dilepas kuncinya.untuk melepaskan keren pada jangkar terlebih dahulu dilakukan pemenasan dengan menggunakan boiller agar perekat pada jangkar yang sekaligus berfungsi sebagai isolator (mika) mengelupas. Setelah barulah keren-keren dilepas satu persatu dengan menggunakan cutter. Keren-keren yang sudah terpisah dibuaka kuncinya yang terdapan pada satu-persatu keren tersebut. Setelah itu barulah keren-keren tersebut digabungkan kembali sehingga menjadi jangkar kembali. Cara untuk memasang keren agar menjadi jangkar kembali ialah keren tersebut dimasukkan kembali pada poros rotor. Untuk memasang keren ini menggunakan alat bantu pembuka puller (traker). Berikut adalah hasil modifikasi alur jangkar motor DC.

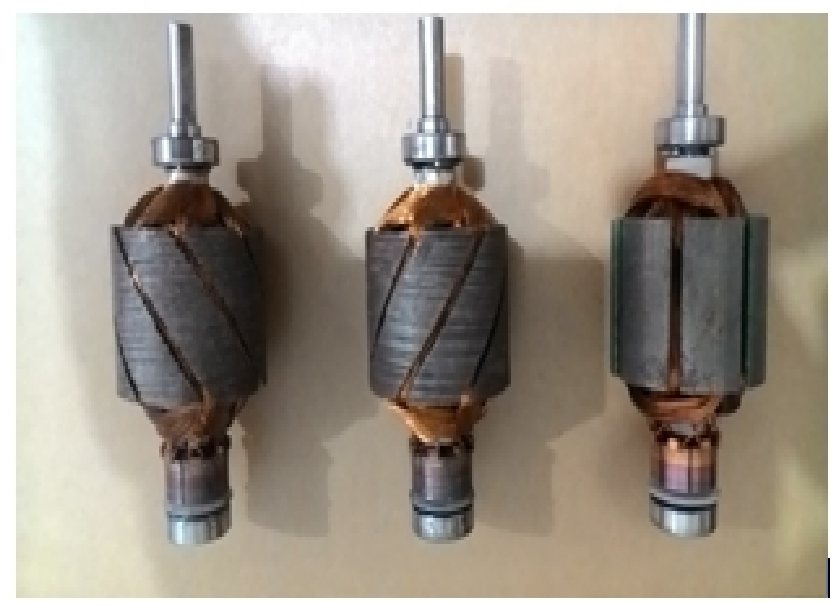

Gambar 7. Jangkar motor DC alur lurus, miring 30 derajat ke kanan dan ke kiri

\section{B. Analisa Pengaruh Perubahan Sudut dan Arah Alur Jangkar Motor DC}

Pada penelitian ini dilakukan analisis pengaruh perubahan sudut alur jangkar motor DC terhadap nilai RPM dan Torsi pada motor DC. Ada dua motor DC yang dilakukan modifikasi yaitu motor DC dengan alur miring 30 derajat ke kanan dan motor DC dengan alur miring ke kiri 30 derajat ke kiri. Dari kedua motor DC yang telah dimodifikasi akan dianalisa pengaruh perubahan arah sudut, namun dengan besar sudut kemiringan yang tetap sama yaitu $30^{\circ}$. Dari data hasil pengujian yang telah dilakuakan diperoleh data RPM dan torsi pada masing masing motor DC normal, motor DC miring 30 derajat ke kanan dan ke kiri. Dari pengujian motor DC ketiga motor maka diperoleh nilai RPM pada Tabel 2.

Dari analisa grafik pada gambar 8. perbandingan nilai RPM motor DC dari ketiga motor Normal, Kanan dan Kiri, terlihat bahawa RPM akan semakin besar jika tegangan yang masuk ke rotor motor DC semakin besar. Hal ini sesuai dengan teori yang menyatakan bahawa kecepatan putar motor berbanding lurus dengan tegangan yang masuk pada motor. Dari ketiga nilai RPM motor DC terlihat nilai RPM pada motor DC yang telah dimodifikasi baik miring ke kanan maupun ke kiri memiliki nilai RPM yang lebih besar daripada nilai RPM motor DC Normal. Sedangkan nilai RPM motor DC miring ke kanan dan miring ke kiri memliki nilai RPM yang hampir sama. hal ini disebabkan karana ada perubahan kemiringan alur pada rotor motor DC sehingga mejadikan nilai RPM pada motor DC lebih besar.

Tabel 2. Nilai RPM motor DC

\begin{tabular}{cccc}
\hline Tegangan (V) & \multicolumn{3}{c}{$\begin{array}{c}\text { Kecapatan putar (RPM) } \\
\text { Motor DC } \\
\text { Kanan }\end{array}$} \\
\hline 6 & Normal & 870,1 & Kiri \\
\hline 8 & 1160,7 & 1198 & 869,7 \\
10 & 1458 & 1521 & 1200 \\
12 & 1762 & 1858 & 1525 \\
14 & 2064 & 2179 & 1852 \\
16 & 2364 & 2510 & 2180 \\
18 & 2660 & 2839 & 2506 \\
20 & 2965 & 3174 & 2838 \\
22 & 3271 & 3515 & 3176 \\
24 & 3569 & 3823 & 3508 \\
\hline
\end{tabular}

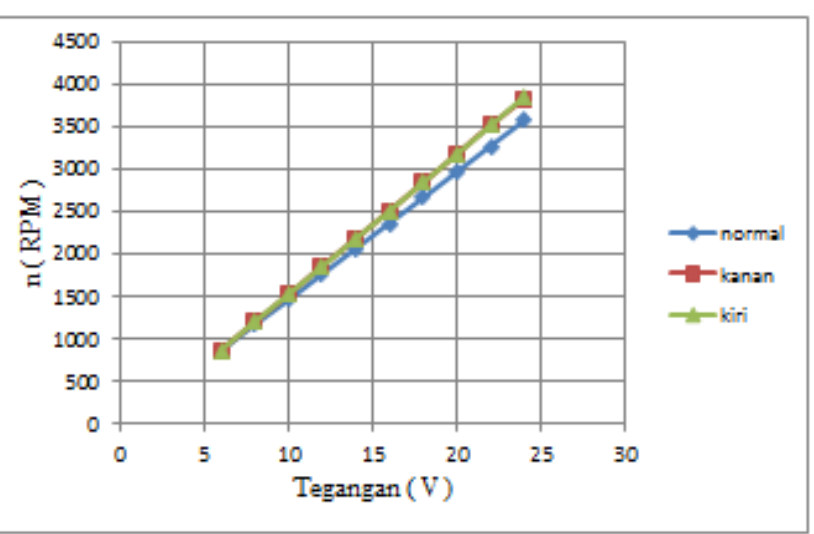

Gambar 8. Grafik perbandingan nilai RPM motor DC

Dari data torsi motor DC yang diperoleh pada tabel 3 . dapat dilihat bahwa torsi pada motor DC kanan dan kiri memiliki nilai torsi yang lebih kecil dibanding nilai torsi pada motor DC normal. Hal ini disebabakan karana berubahnya derajat alur, yang semula alur jangkar motor DC sebesar 90 derajat dirubah sebesar 30 derajat ke kanan dan ke kiri. Untuk nilai torsi motor DC kanan dan kiri, memiliki nilai torsi yang sama. Untuk torsi awal motor DC alur jangkar yang dimodifikasi lebih besar dibandingkan 
motor DC normal, hal dipengaruhi oleh besar arus yang masuk pada motor DC yang dimodifikasi lebih besar daripada arus pada motor DC normal. Nilai torsi motor DC normal lebih besar dibanding motor DC kanan dan kiri ketiga tegangan $16 \mathrm{v}$ sampai $24 \mathrm{v}$. Hal ini dapat dilihat pada grafik perbandingan nilai torsi motor DC. Hasil grafik torsi motor DC dapat dilihat pada gambar 9.

\section{Analisa Kerja Motor DC pada Tegangan Nominal}

Pada penelitian ini dilakukan analisa torsi dan RPM motor DC pada saat motor DC bekerja atau berputar dengan tegangan nominal. Tegangan nominal motor DC pada penelitian ini adalah sebesar $24 \mathrm{~V}$. Motor DC akan bekerja maksimal pada saat diberikan tegangan nominal. Saat motor DC diberikan tegangan nominalakan diperoeleh arus, RPM , Torsi dan daya yang maksimal.

Dari data tabel 4 hasil pengujian motor DC pada saat motor bekerja dengan tegangan nominal sebesar 24 V. Dari ketiga motor DC yang telah dilakukan pengujian dengan tegangan yang masuk pada motor sama $24 \mathrm{v}$ diperoeleh arus yang sama sebesar $0,17 \mathrm{~A}$. Dari tegangan dan arus yang diperoleh dari pengujian ke tiga motor DC, maka akan didapat besar daya yang masuk pada motor DC sama yaitu sebesar 4,08 watt.

Tabel 3. Nilai torsi motor DC

\begin{tabular}{ccccccc}
\hline $\begin{array}{c}\text { Tegangan } \\
\text { (V) }\end{array}$ & \multicolumn{2}{c}{ Normal } & \multicolumn{2}{c}{ Motor DC } \\
Arusan & Torsi & \multicolumn{2}{c}{ Arus } & Torsi & Arus & Torsi \\
& $(\mathrm{I})$ & $(\mathrm{Nm})$ & $(\mathrm{I})$ & $(\mathrm{Nm})$ & $(\mathrm{I})$ & $(\mathrm{Nm})$ \\
\hline 6 & 0,11 & 0,00733 & 0,13 & 0,00856 & 0,13 & 0,00857 \\
8 & 0,12 & 0,00785 & 0,13 & 0,00829 & 0,14 & 0,00892 \\
10 & 0,13 & 0,00852 & 0,14 & 0,00879 & 0,14 & 0,00877 \\
12 & 0,14 & 0,00911 & 0,15 & 0,00926 & 0,14 & 0,00867 \\
14 & 0,14 & 0,00907 & 0,15 & 0,00921 & 0,15 & 0,0092 \\
16 & 0,15 & 0,0097 & 0,15 & 0,00914 & 0,15 & 0,00915 \\
18 & 0,15 & 0,0097 & 0,15 & 0,00909 & 0,16 & 0,0097 \\
20 & 0,16 & 0,01031 & 0,16 & 0,00963 & 0,17 & 0,01023 \\
22 & 0,16 & 0,01028 & 0,17 & 0,01017 & 0,17 & 0,01019 \\
24 & 0,17 & 0,01092 & 0,17 & 0,0102 & 0,17 & 0,0102 \\
\hline
\end{tabular}

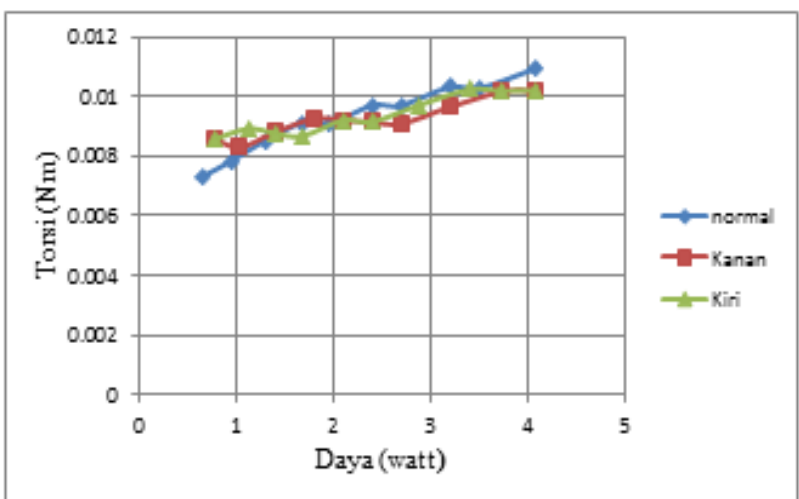

Gambar 9. Grafik perbandingan nilai torsi motor DC

Untuk nilai RPM pada tegangan $24 \mathrm{~V}$ diperoleh kecepatan putar pada motor DC Normal sebesar $3569 R P M$, motor DC kanan sebesar $3823 R P M$, dan motor DC Kiri sebesar $3849 R P M$. Dari data hasil pengujian motor DC pada Tegangan nominal, motor DC yang dimodifikasi memiliki RPM yang lebih baik. Motor DC alur jangkar miring $30^{\circ}$ ke kanan dan ke kiri masingmasing memiliki RPM sebesar $3823 R P M$ dan $3849 R P M$, nilai RPM tersebut lebih besar dibanding RPM pada motor DC normal sebesar $3569 R P M$.
Sedangkan nilai RPM dari motor DC yang telah dimodifikasi memiliki nilai yang hampir sama yaitu sebesar $3800 R P M$ lebih.

Untuk nilai Torsi pada tegangan $24 \mathrm{~V}$ pada motor DC masing-asing untuk motor DC normal diperoleh torsi sebesar 0,01092 $\mathrm{Nm}$, torsi motor DC kanan sebesar $0,0102 \mathrm{Nm}$, dan torsi motor DC kiri sebesar $0,0102 \mathrm{Nm}$. dari data hasil pengujian torsi motor DC, dapat dilihat bahwa torsi motor DC normal memiliki nilai torsi yang lebih tinggi daripada nilai torsi motor DC yang telah dimodifikasai miring ke kanan dan miring ke kiri. Sedangkan untuk besar nilai torsi motor DC miring ke kanan dan miring ke kiri memiliki nilai torsi yang sama.

Motor DC alur jangkar miring ke kanan dan ke kiri memiliki nilai RPM yang lebih besar dan Torsi yang lebih kecil dibandingkan dengan motor DC alur lurus atau Normal disebabkan karena perubahan sudut alur. Hal ini sesui dengan rumus $T=B \quad I \quad L \quad r \sin \theta$. Dari nilai teta terlihat bahwa motor DC alur lurus akan memiliki torsi yang lebih besir dibanding motor DC alur jangkar miring kanan dan kiri yaitu $1: 0,866$. Sedangkan untuk nilai torsi motor DC alur jangkar miring kanan dan kiri memiliki nilai torsi yang sama, hal ini dapat dilihat pada perbandingan nilai $\sin \theta^{\circ}$ yang memiliki nilai yang sama sebesar 0,866 . Untuk nilai RPM pada motor DC alur jangkar modifikasi miring kanan dan kiri memiliki nili RPM yang lebih besar dibanding dengan nili RPM motor DC normal karena nilai RPM dan Torsi berbanding Terbalik, hal ini sesuai dengan persamaan $n=\frac{P 60}{T 2 \pi}$. Dari hasil pengujian motor DC, motor DC normal memiliki nilai RPM yang lebih kecil dan Torsi yang lebih besar dibandingkan nilai RPM dan Torsi pada motor DC yang telah dimodifikasi.

Tabel 4. Data hasil pengujian motor DC pada tegangan nominal

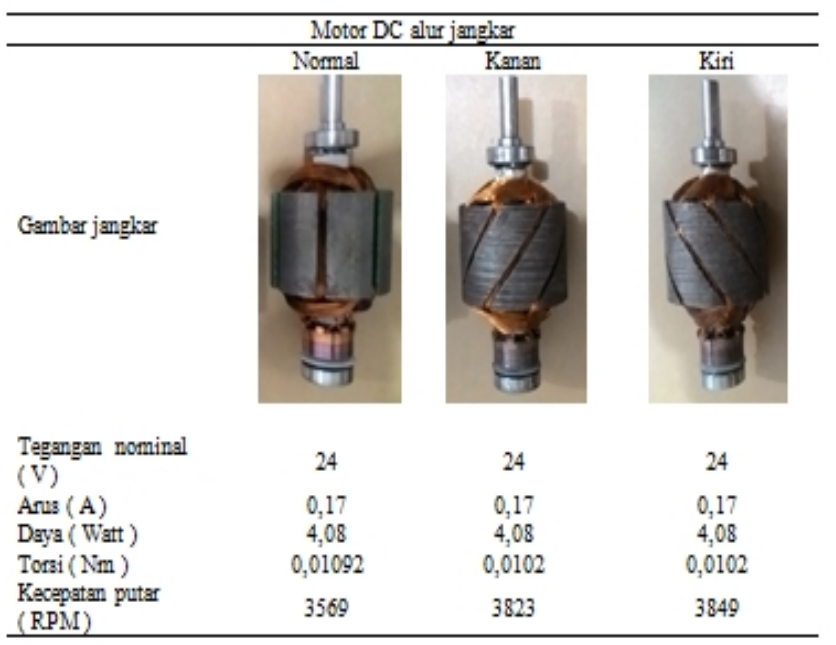

\section{KESIMPULAN}

Berdasarkan penelitian tentang pengaruh perubahan kemiringan sudut alur dan arah miring sudut alur pada motor DC magnet permanent dapat diambil beberapa 
kesimpulan sebagai berikut:

1. Dengan mengubah derajat kemiringan alur jangkar motor DC sebesar 30 derajat baik ke kanan maupun ke kiri, akan memperbesar nilai RPM pada motor DC dan memperkecil nilai Torsi pada motor DC.

2. Dengan menggubah arah kemiringan dengan besar derajat yang sama sebesar 30 derajat akan diperoleh hasil RPM dan Torsi yang sama pada Motor DC.

3. Pada saat motor DC bekerja pada tegangan nominal 24 $\mathrm{V}$, diperoeleh nilai torsi motor DC normal yang lebih besar yaitu $0,01092 \mathrm{Nm}$ daripada torsi pada motor DC miring ke kanan dan miring ke kiri yaitu sama sama memeiliki torsi sebesar $0,0102 \mathrm{Nm}$.

4. Pada saat motor DC bekerja pada tegangan nominal 24 $\mathrm{V}$, motor DC yang telah dimodifikasi 30 derajat ke kanan dan ke kiri memiliki RPM yang lebih besar daripada motor DC Normal yaitu 3823 dan 3849 dan RPM normal 3569.

\section{SARAN}

Dari hasil penelitian penulis menyarankan untuk dilakukan penelitian dengan membandingkan besar sudut alur jangkar. Saat melakukan modifikasi jangkar rotor dengan variasi sudut sebesar $30^{\circ}, 45^{\circ}, 60^{\circ}, 90^{\circ}$ dan pengujian dilakukan dengan menggunakan beban.

\section{DAFTAR PUSTAKA}

[1] Santoso, A. H. 2012. Kajian Pengaruh Modifikasi Jumlah Kutub Terhadap Perubahan Daya Dan Torsi Motor Induksi.

[2] Saputra, E. 2013. Analisis Efisiensi Motor DC Seri Akibat Pergeseran Sikat. vol.2 no.3.

[3] Mardika, N. 2008. Analisa Karakteristik PutaranTorsi Motor Arus Searah Penguatan Shunt Berkutub Bantu. 30-33, 29-38, 27-28, 15, 29, 18-23.

[4] Chapman, S. J. 2005. Electric Machinery Fundamentals Fourth Edtion. New York: McGrawHill

[5] Zumain, M. A. 2009. Prototipe Mobil Listrik dengan Menggunakan Motor Dc 0.37 HP. 11-14. 